\title{
Diffusion and Atomic Mobilities in fcc Ni-Sn Alloys
}

\author{
J. Wang, C. Leinenbach, H.S. Liu, L.B. Liu, M. Roth, and Z.P. Jin
}

(Submitted May 25, 2009; in revised form September 15, 2009)

\begin{abstract}
The composition-distance profiles in face-centered cubic (fcc) Ni-Sn alloys at 1173, 1223, 1273, and $1323 \mathrm{~K}$ were measured by means of electronic probe microanalysis (EPMA) using $\mathrm{Ni} / \mathrm{Ni}$-7.3at.\%Sn diffusion couples. Based on the available thermodynamic information and various experimental diffusion coefficients, the atomic mobilities of $\mathrm{Ni}$ and $\mathrm{Sn}$ in fce Ni-Sn alloys were assessed as a function of temperature and composition in terms of the CALPHAD method using the DICTRA ${ }^{\circledR}$ software package. Optimized mobility parameters are presented. Comparisons between the calculated and measured diffusion coefficients show that most of the experimental information can be reproduced reasonably. The obtained mobility parameters can also predict satisfactorily the composition-distance profiles of the $\mathrm{Ni} / \mathrm{Ni}-7.3 \mathrm{at} . \% \mathrm{Sn}$ diffusion couples determined in the present work.
\end{abstract}

Keywords atomic mobility, CALPHAD, DICTRA, diffusion, $\mathrm{Ni}-\mathrm{Sn}$ alloys

\section{Introduction}

Sn-based alloys with different additives (Ag, $\mathrm{Bi}, \mathrm{Cu}, \mathrm{In}$, $\mathrm{Sb}, \mathrm{Zn}$ etc.) are promising and potential candidates for $\mathrm{Pb}$-free solders in the modern electronic industry. ${ }^{[1-4]}$ On the other hand, $\mathrm{Cu} / \mathrm{Au} / \mathrm{Ni}$ layers as substrates or under bump metallurgy (UBM) layers have been commonly employed in modern electronic packaging. ${ }^{[5-15]}$ The diffusion behavior between $\mathrm{Sn}$ and Ni affects the microstructure evolution and the formation of intermetallic compounds at the interface between the Sn-based solders and the Ni-containing substrates or UBM layers, which has significant influence on the reliability of the solder joints and then on the mechanical and electrical properties of the electronic devices. ${ }^{[5,6,9-15]}$

The diffusion data of $\mathrm{Sn}$ and $\mathrm{Ni}$ in the Ni-Sn binary system is indispensable to better understand interdiffusion between $\mathrm{Sn}$ and $\mathrm{Ni}$ and thus to help to control the interfacial microstructure evolution as well as to predict the lifetime of the solder joints for electronic devices. However, only three reports on experimental diffusion measurements can be found in the literature. Vladimirov et al. ${ }^{[16]}$ and Marchive et al. ${ }^{[17]}$ reported the impurity diffusion coefficients of $\mathrm{Sn}$ in pure $\mathrm{Ni}$ by the radiometric analysis. Iijima et al. ${ }^{[18]}$

J. Wang, EMPA, Swiss Federal Laboratories for Materials Testing and Research, Laboratory for Joining and Interface Technology, Überlandstrasse 129, CH-8600 Dübendorf, Switzerland and School of Materials Science and Engineering, Central South University, Changsha, Hunan 410083, P. R. China; C. Leinenbach and M. Roth, EMPA, Swiss Federal Laboratories for Materials Testing and Research, Laboratory for Joining and Interface Technology, Überlandstrasse 129, CH-8600 Dübendorf, Switzerland; and H. S. Liu, L. B. Liu, and Z. P. Jin, School of Materials Science and Engineering, Central South University, Changsha, Hunan 410083, P. R. China. Contact e-mail: jiang.wang@empa.ch. measured interdiffusion coefficients and intrinsic coefficients of $\mathrm{Sn}$ and $\mathrm{Ni}$ in fcc Ni-Sn alloys in the temperature range between 1223 and $1473 \mathrm{~K}$ using semi-infinite diffusion couples with Kirkendall markers. Using ${ }^{63} \mathrm{Ni}$ and ${ }^{113} \mathrm{Sn}$ as tracing elements, the tracer diffusion coefficients of $\mathrm{Ni}$ and Sn in fcc Ni-Sn alloys at $1373 \mathrm{~K}$ were also determined by Iijima et al. ${ }^{[18]}$ through the residual activity method and serial sectioning method, respectively.

In order to obtain a full understanding of diffusion in fcc $\mathrm{Ni}$-Sn alloys, the combination of diffusion experiments and kinetic simulations are needed. In the present work the composition-distance profiles of the Ni/Ni-7.3at.\%Sn diffusion couples at different temperatures were determined firstly. Then, the atomic mobilities of Ni and $\mathrm{Sn}$ in fcc Ni-Sn alloys were assessed as a function of temperature and composition by means of the CALPHAD method using the DICTRA $^{\circledR}$ (DIffusion Controlled TRAnsformation) software package, ${ }^{[19-23]}$ which has been used successfully to simulate various phase transformation processes based on sharp interface and local equilibrium hypothesis. ${ }^{[24-29]}$ Finally, we can compare the calculated compositiondistance profiles of the $\mathrm{Ni} / \mathrm{Ni}-7.3$ at.\% $\%$ diffusion couple with experimental data measured in the present work by applying the assessed mobility parameters.

\section{Experimental Procedure}

Ni-7.3at.\%Sn alloys were prepared in an arc-melting furnace (WKDHL-I, Opto-electronics Co. Ltd., Beijing, China) under a high purity argon atmosphere using $\mathrm{Ni}$ (purity 99.99\%) and Sn (purity 99.999\%). No chemical analysis for these alloy ingots were conducted because the weight loss is less than $0.5 \mathrm{wt} . \%$ during arc-melting. In order to promote grain growth and decrease grain boundary diffusion, the alloy ingots and $\mathrm{Ni}$ blocks were annealed in sealed quartz tubes in vacuum of $1 \times 10^{-3} \mathrm{~Pa}$ at $1273 \pm 2 \mathrm{~K}$ for $130 \mathrm{~h}$. Afterwards, the tubes were taken out from the furnace and quenched into water. Then, diffusion couples 
were assembled from the obtained Ni-7.3at.\%Sn alloys and pure Ni blocks by pressure diffusion welding at $873 \mathrm{~K}$ under Ar flow for $15 \mathrm{~min}$. Subsequently, the diffusion couples were encapsulated in evacuated quartz tubes backfilled with pure argon and annealed at $1173 \pm 2$, $1223 \pm 2,1273 \pm 2$, and $1323 \pm 2 \mathrm{~K}$ for $420,360,264$, and $180 \mathrm{~h}$, respectively. After diffusion annealing, the diffusion couples were taken out from the furnace and cooled down rapidly by breaking the quartz tubes in water. Finally, after the standard metallographic preparation, the composition-distance profiles of $\mathrm{Sn}$ in $\mathrm{Ni} / \mathrm{Ni}-7.3$ at. $\% \mathrm{Sn}$ diffusion couples in the diffusion zone were determined quantitatively by the electron probe micro-analysis (EPMA) on a JEOL JXA-8800R (Japan Electron Optics Ltd., Tokyo, Japan) microprobe under the operating conditions of $20 \mathrm{kV}$, $20 \mathrm{nA}$ current, and a $40^{\circ}$ take-off angle. Pure element standards provided by JEOL were used for calibration. The measurements have a relative accuracy of about $1 \%$.

\section{Modeling of Atomic Mobility}

The temporal profile of the diffusing species $k$ is given by the Fick's law in the mass conservation form as follows:

$\frac{\partial C_{k}}{\partial t}=-\operatorname{div}\left(J_{k}\right)$

where $C_{k}$ is the concentration in moles per volume, and div denotes the divergence operator. The diffusional flux of the species, $J_{k}$, in a multicomponent system is given by the Fick-Onsager law as:

$J_{k}=-\sum_{j=1}^{n-1} D_{k j}^{n} \nabla C_{j}$

$D_{k j}^{n}$ is the chemical diffusion coefficient. The summation is performed over $(n-1)$ independent concentration as the dependent $n$ component may be taken as the solvent. $D_{k j}^{n}$ in a substitutional solution phase is given by the following $\operatorname{expression}^{[21,22]}$ :

$D_{k j}^{n}=\sum_{i}\left(\delta_{i k}-x_{k}\right) x_{i} M_{i}\left(\frac{\partial \mu_{i}}{\partial x_{j}}-\frac{\partial \mu_{i}}{\partial x_{n}}\right)$

where $\delta_{i k}$ is the Kroneker delta $\left(\delta_{i k}=1\right.$ if $i=k$, otherwise $\left.\delta_{i k}=0\right), x_{i}$ the mole fraction, $\mu_{i}$ the chemical potential of element $i$ and $M_{i}$ the composition dependent atomic mobility.

From the absolute reaction rate theory, the mobility parameters $M_{i}$ for the element $i$, can be divided into a frequency factor $M_{i}^{0}$ and an activation enthalpy $Q_{i}$. According to the suggestion by Jönsson, ${ }^{[30-32]}$ the $M_{i}$ can be expressed as:

$M_{i}=\exp \left(\frac{R T \ln M_{i}^{0}}{R T}\right) \exp \left(\frac{-Q_{i}}{R T}\right) \frac{1}{R T}$

where $R$ is the gas constant and $T$ is the temperature. Both $M_{i}^{0}$ and $Q_{i}$ are dependent on temperature, composition, and pressure. The parameters $R T$ In $M_{i}^{0}$ and $Q_{i}$ can be combined into one parameter $\Delta G_{i}^{*}=-Q_{i}+R T \ln M_{i}^{0}$. Equation (4) can be simplified to as:

$M_{i}=\exp \left(\frac{\Delta G_{i}^{\phi}}{R T}\right) \frac{1}{R T}$

Similar to the phenomenological CALPHAD method, Andersson and $\AA$ gren ${ }^{[22]}$ suggested the parameter $\Delta G_{i}^{*}$ is assumed to be a function of composition, which can be expressed by a Redlich-Kister polynomial. ${ }^{[33]}$ For fcc Ni-Sn alloys, $\Delta G_{i}^{*}$ is given as follows:

$$
\begin{aligned}
\Delta G_{i}^{*}= & x_{\mathrm{Ni}} \Delta G_{i}^{\mathrm{Ni}}+x_{\mathrm{Sn}} \Delta G_{i}^{\mathrm{Sn}} \\
& +x_{\mathrm{Ni}} x_{\mathrm{Sn}} \sum_{j=0}^{n} \Delta^{(j)} G_{i}^{\mathrm{Ni}, \mathrm{Sn}}\left(x_{\mathrm{Ni}}-x_{\mathrm{Sn}}\right)^{j}
\end{aligned}
$$

where $\Delta G_{i}^{\mathrm{Ni}}$ and $\Delta G_{i}^{\mathrm{Sn}}$ are the values of $\Delta G_{i}^{\phi}$ for fcc(Ni) and hypothetical fcc(Sn), respectively, and thus represent the endpoint values in the composition space, while $\Delta^{(j)} G_{i}^{\mathrm{Ni}, \mathrm{Sn}}$ is the binary interaction term for diffusion between $\mathrm{Ni}$ and $\mathrm{Sn}$.

\section{Results and Discussion}

In order to extract the mobility parameters, reasonable thermodynamic descriptions are required for calculating the thermodynamic factor. The thermodynamic database of the Ni-Sn binary system from Liu et al. ${ }^{[34]}$ has been used in the present work, which can reproduce the phase diagram and most of thermodynamic data. Figure 1 is the calculated phase diagram of the Ni-Sn binary system and Fig. 2 shows the thermodynamic factor $(\phi)$ in fcc Ni-Sn alloys at different temperatures. The mobility parameters of $\mathrm{Ni}$ in $\mathrm{fcc}(\mathrm{Ni})$ and

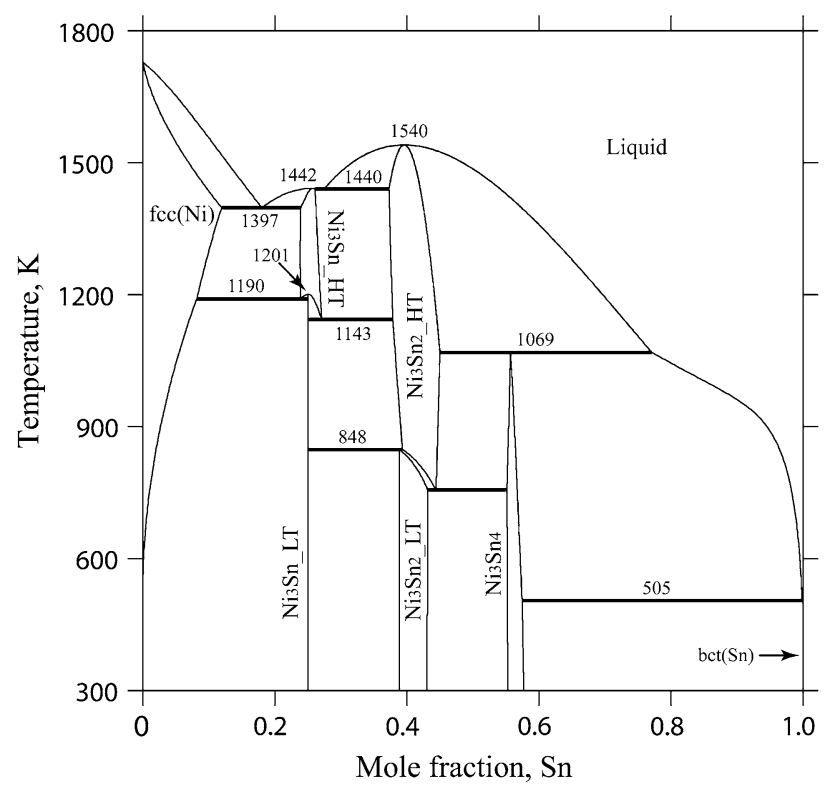

Fig. 1 Calculated phase diagram of the Ni-Sn binary system from Liu et al. ${ }^{[34]}$ 


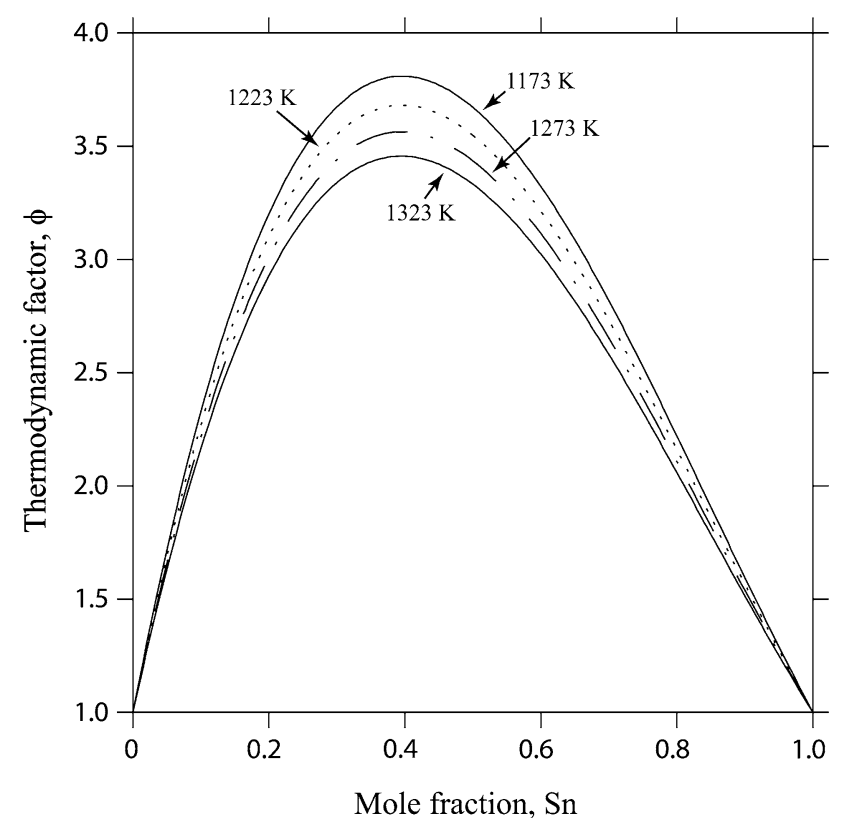

Fig. 2 Calculated thermodynamic factor $(\phi)$ of the fcc phase in the Ni-Sn binary system at the different temperatures using the data by Liu et al. ${ }^{[34]}$

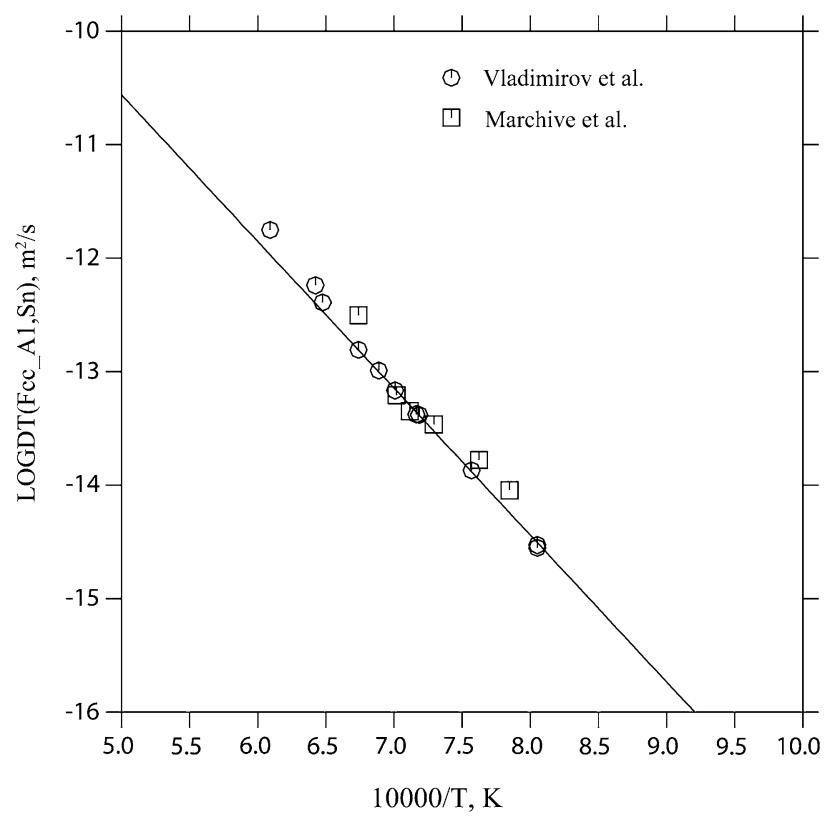

Fig. 3 Calculated temperature dependence of $\mathrm{Sn}$ tracer diffusion coefficients in pure $\mathrm{Ni}$ with experimental data ${ }^{[16,17]}$

Table 1 Mobility parameters of the face-centered cubic Ni-Sn alloys

\begin{tabular}{|c|c|c|}
\hline Mobility & Parameters(a) & Reference \\
\hline \multirow[t]{3}{*}{ Mobility of Ni } & $\Delta G_{\mathrm{Ni}}^{\mathrm{Ni}}=-287000+R T \ln \left(2.259 \times 10^{-4}\right)$ & [35] \\
\hline & $\Delta G_{\mathrm{Ni}}^{\mathrm{Sn}}=-59345+R T \ln \left(3.477 \times 10^{-5}\right)$ & [36] \\
\hline & $\Delta^{0} G_{\mathrm{Ni}}^{\mathrm{Ni}, \mathrm{Sn}}=+650787-247.3 \times T$ & This work \\
\hline \multirow[t]{3}{*}{ Mobility of Sn } & $\Delta G_{\mathrm{Sn}}^{\mathrm{Sn}}=-59345+R T \ln \left(3.477 \times 10^{-5}\right)$ & [36] \\
\hline & $\Delta G_{\mathrm{Sn}}^{\mathrm{Ni}}=-247479+R T \ln \left(7.961 \times 10^{-5}\right)$ & This work \\
\hline & $\Delta^{0} G_{\mathrm{Sn}}^{\mathrm{Ni}, \mathrm{Sn}}=-428873+217.7 \times T$ & \\
\hline
\end{tabular}

(a) Note: The units are $\mathrm{J} /(\mathrm{mol}$ atoms), while the parameters $R$ and $T$ are the gas constant and temperature, respectively

Sn in fcc(Sn) have been assessed by Jönsson ${ }^{[35]}$ and Wang et al., ${ }^{[36]}$ respectively, and are adopted in the present work. Besides them, according to Eq (6), the impurity diffusion coefficients of $\mathrm{Ni}$ in hypothetical $\mathrm{fcc}(\mathrm{Sn})$ are required but cannot be measured experimentally. Therefore, the impurity diffusion coefficients of $\mathrm{Ni}$ in hypothetical $\mathrm{fcc}(\mathrm{Sn})$ is set equal to the self-diffusivity of $\mathrm{Sn}$ in $\mathrm{fcc}(\mathrm{Sn})$, and the mobility parameters of $\mathrm{Sn}$ in $\mathrm{fcc}(\mathrm{Ni})$ is subject to the optimization in the present work.

All optimizations for obtaining the atomic mobilities have been performed in the PARROT module of the DICTRA $^{\circledR}$ software package. ${ }^{[21-23]}$ This module works by minimizing the square sum of the differences between experimental data and calculated values. In the present optimization, the experimental data of impurity diffusion coefficients, tracer diffusion coefficients, intrinsic diffusion coefficients and interdiffusion coefficients reported by Vladimirov et al., ${ }^{[16]}$ Marchive et al., ${ }^{[17]}$ and Iijima et al. ${ }^{[18]}$ were employed to assess the mobility parameters of Ni and Sn for the face-centered cubic (fcc) Ni-Sn alloys. The mobility parameters used and obtained finally in the present work are summarized in Table 1.

Figure 3 illustrates the calculated temperature dependence of $\mathrm{Sn}$ impurity diffusion coefficients in pure $\mathrm{Ni}$ with experimental data. ${ }^{[16,17]}$ The calculated values are in good agreement with experimental data measured by Vladimirov et al. ${ }^{[16]}$ and Marchive et al. ${ }^{[17]}$ Comparisons between the calculated tracer diffusion coefficients of $\mathrm{Sn}$ and $\mathrm{Ni}$ at $1373 \mathrm{~K}$ in the Ni-rich Ni-Sn alloys with experimental data ${ }^{[18]}$ are given in Fig. 4. Although a small difference exists between the calculated values and the measured data by Iijima et al., ${ }^{[18]}$ the calculated results are reasonable and acceptable in the present work if considering that the experimental error of diffusion data is normally within one or two orders of magnitude.

Figure 5 compares the calculated intrinsic diffusion coefficients of $\mathrm{Ni}$ and $\mathrm{Sn}$ at $1373 \mathrm{~K}$ in the Ni-rich Ni-Sn alloys. The calculated intrinsic diffusion coefficients of $\mathrm{Sn}$ 


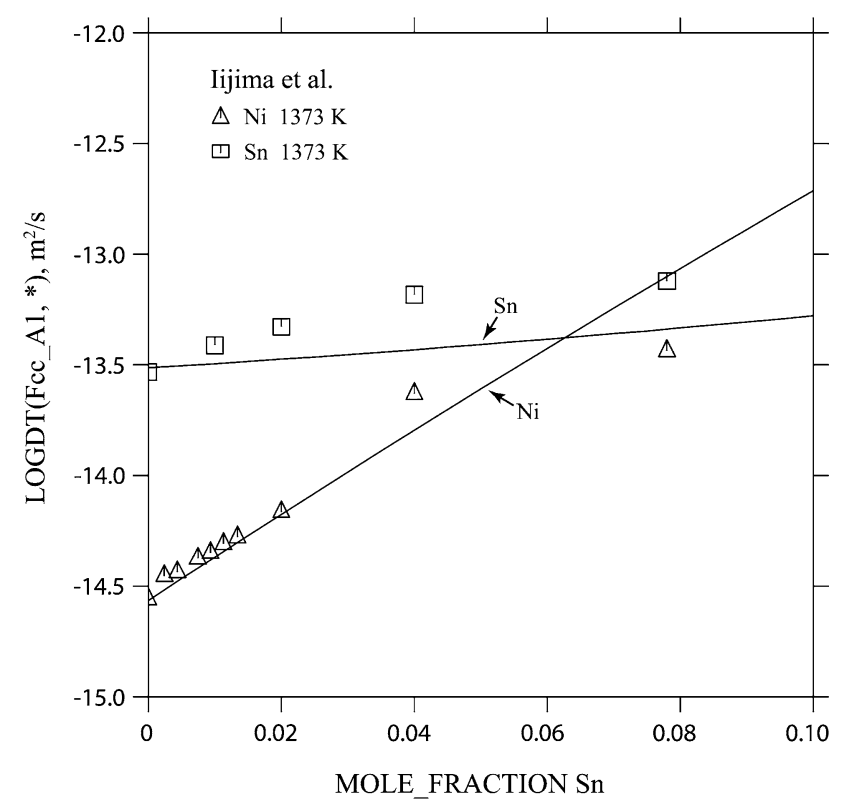

Fig. 4 Calculated tracer diffusion coefficients of $\mathrm{Sn}$ and $\mathrm{Ni}$ in fcc Ni-Sn alloys at $1373 \mathrm{~K}$ with experimental data ${ }^{[18]}$

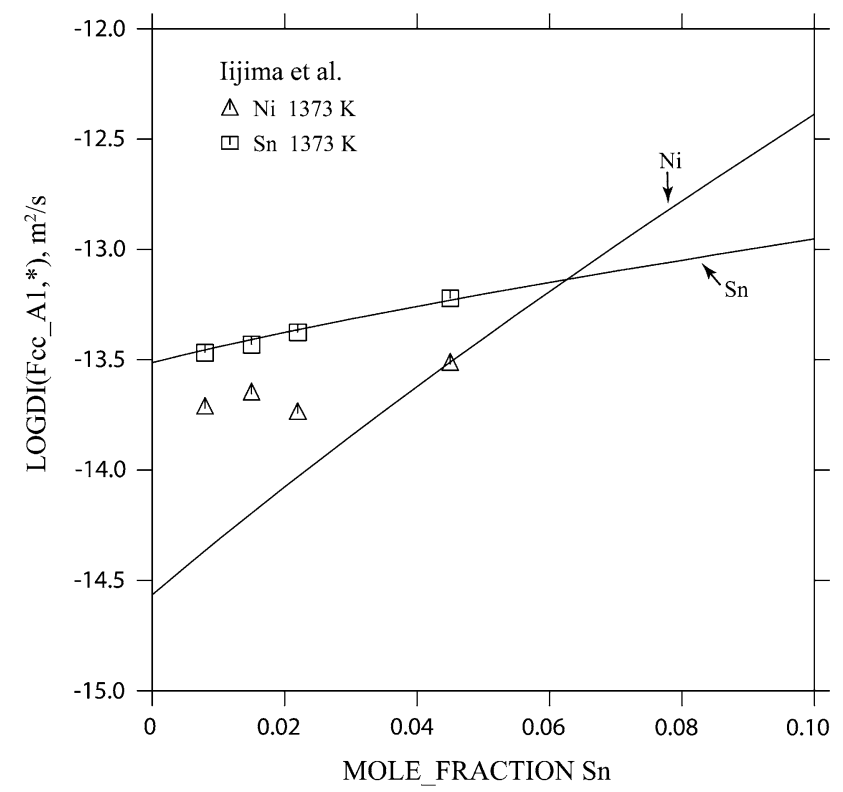

Fig. 5 Comparison of the intrinsic diffusion coefficients of $\mathrm{Ni}$ and $\mathrm{Sn}$ at $1373 \mathrm{~K}$ in the fcc Ni-Sn alloys with experimental data $^{[18]}$

are in excellent agreement with experimental data measured by Iijima et al. ${ }^{[18]}$ However, the calculated intrinsic diffusion coefficients of $\mathrm{Ni}$ deviate with experimental data measured by Iijima et al. ${ }^{[18]}$ The reasons for this deviation are as follows. On the one hand, the tracer diffusion coefficient of $\mathrm{Ni}$ as shown in Fig. 4 is equal to the intrinsic diffusion coefficient of $\mathrm{Ni}$ given in Fig. 5 and the selfdiffusion coefficient of $\mathrm{Ni}$ at $1373 \mathrm{~K}$ if the content of $\mathrm{Sn}$ in the Ni-Sn alloy is decreasing to zero. Therefore, it is

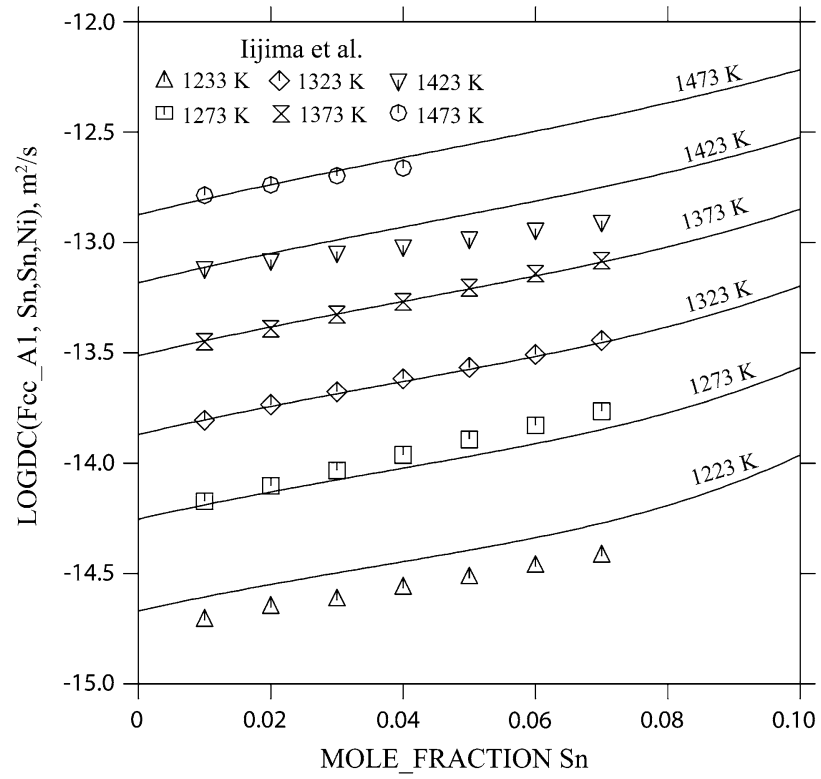

Fig. 6 Comparison of the calculated interdiffusion coefficients in the fcc Ni-Sn alloys at different temperatures with experimental data ${ }^{[18]}$

believed that the tracer diffusion data in Fig. 4 is more easily available than the intrinsic diffusion data in Fig. 5. In the present optimization, a small weight was given to the intrinsic diffusion coefficients of Ni. On the other hand, the mobility parameters of $\mathrm{Ni}$ adopted in the present work have been assessed by Jönsson, ${ }^{[35]}$ which can reproduce most of the experimental data and allows extrapolating to high-order related systems. During the optimization, these parameters were fixed to achieve the self-consistent mobility database of the Ni-based alloys so that this deviation cannot be avoided.

Figure 6 presents the calculated composition dependence of interdiffusion coefficients in the Ni-rich Ni-Sn alloys at different temperatures with experimental data. ${ }^{[18]}$ The calculated interdiffusion coefficients at $1223 \mathrm{~K}$ and $1423 \mathrm{~K}$ show a little deviation from the data reported by Iijima et al. ${ }^{[18]}$ However, the calculated results at 1273, 1323, 1373 , and $1473 \mathrm{~K}$ are generally in accordance with the data measured by Iijima et al. ${ }^{[18]}$

Further validation of the atomic mobility parameters obtained in the present work was performed by checking whether the parameters can describe satisfactorily the composition-distance profiles in the Ni-Sn diffusion couples. Using the optimized mobility parameters through the DICTRA $^{\circledR}$ software package, ${ }^{[21-23]}$ the compositiondistance profiles perpendicular to the interface of the $\mathrm{Ni} / \mathrm{Ni}-7.3$ at.\%Sn diffusion couples were simulated at different temperatures as shown in Fig. 7 and 8. As can be seen, the calculated composition-distance profiles of the $\mathrm{Ni} / \mathrm{Ni}-7.3$ at.\%Sn diffusion couple at 1173, 1223, 1273, and $1323 \mathrm{~K}$ are in excellent agreement with experimental data measured in the present work, respectively. This confirms the validity of the mobility parameters obtained in the present assessment. 

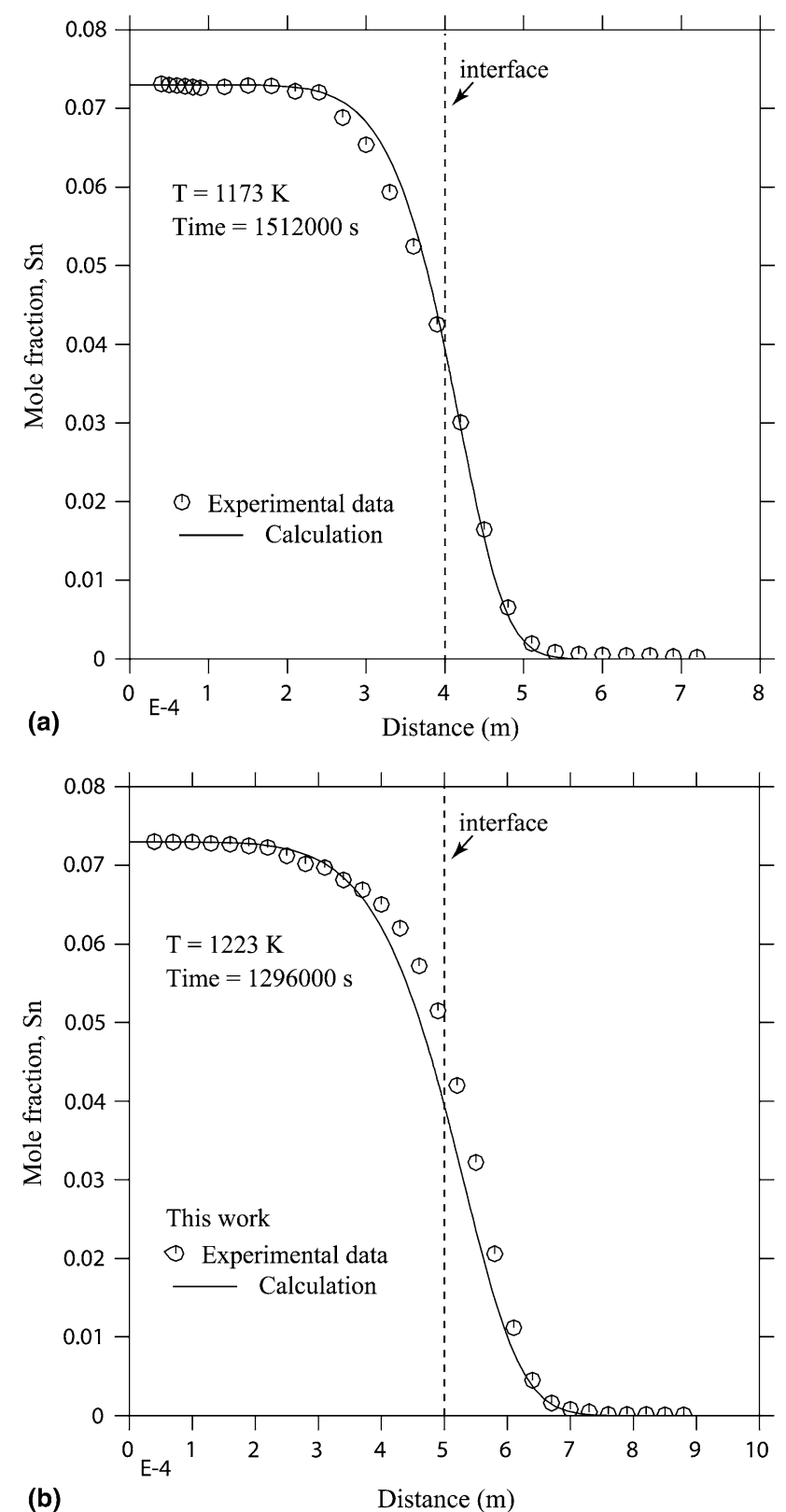

Fig. 7 Calculated composition-distance profiles of the $\mathrm{Ni} / \mathrm{Ni}$ 7.3at.\% Sn diffusion couple with experimental data measured in the present work. (a) $1173 \mathrm{~K}$ for $420 \mathrm{~h}$; (b) $1223 \mathrm{~K}$ for $360 \mathrm{~h}$

\section{Conclusion}

The composition-distance profiles of the $\mathrm{Ni} / \mathrm{Ni}$ 7.3at.\%Sn diffusion couples at 1173, 1223, 1273, and $1323 \mathrm{~K}$ were measured by means of electronic probe microanalysis (EPMA). Combined with the available thermodynamic data and various experimental diffusion coefficients, the atomic mobilities of $\mathrm{Ni}$ and $\mathrm{Sn}$ in face-centered cubic Ni-Sn alloys as a function of temperature and composition have been assessed using the DICTRA ${ }^{\circledR}$ software package. The optimized mobility parameters can be employed to reproduce satisfactorily most of the
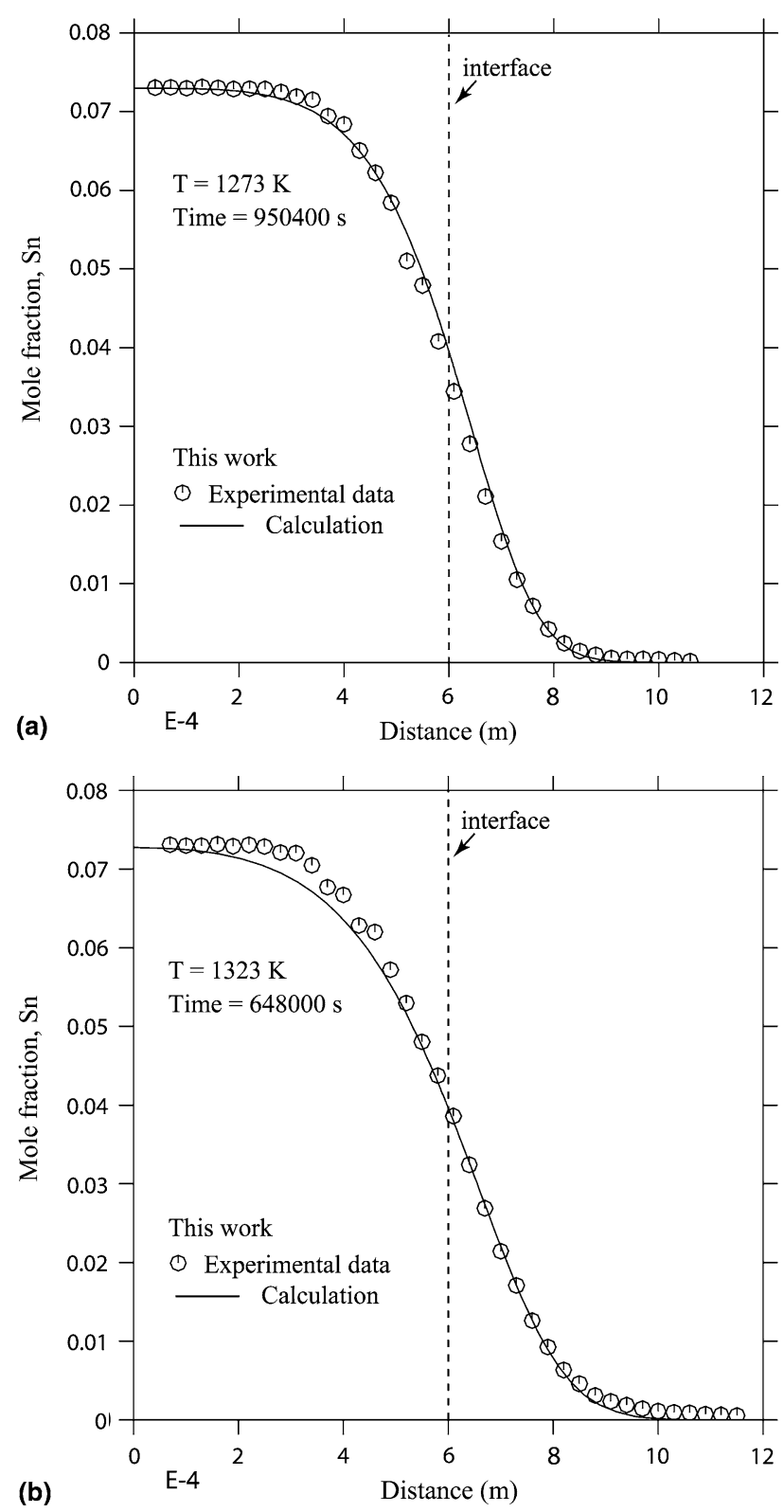

Fig. 8 Calculated composition-distance profiles of the $\mathrm{Ni} / \mathrm{Ni}$ 7.3at.\%Sn diffusion couple with experimental data measured in the present work. (a) $1273 \mathrm{~K}$ for $264 \mathrm{~h}$; (b) $1323 \mathrm{~K}$ for $180 \mathrm{~h}$

experimental information on the measured diffusion coefficients in face-centered cubic Ni-Sn alloys. Furthermore, the composition-distance profiles determined in the present work can be also predicted with reasonable accuracy.

\section{Acknowledgments}

This work was financially supported by National Science Foundation of China (Grant No. 50371104, 50671122). The authors J. Wang, H.S. Liu, L.B. Liu, and Z.P. Jin would like to thank Mr. S.T. Li, Shan-Dong University, for his assistance in EPMA. 


\section{References}

1. M.M. Abtewa and G. Selvadurayb, Lead-free Solders in Microelectronics, Mater. Sci. Eng. R, 2000, 27, p 95-141

2. K. Zeng and K.N. Tu, Six Cases of Reliability Study of $\mathrm{Pb}$-free Solder Joints in Electronic Packaging Technology, Mater. Sci. Eng. R, 2002, 38, p 55-105

3. C.M.L. Wu, D.Q. Yu, C.M.T. Law, and L. Wang, Properties of Lead-free Solder Alloys with Rare Earth Element Additions, Mater. Sci. Eng. R, 2004, 44, p 1-44

4. Y. Li and C.P. Wang, Recent Advances of Conductive Adhesives as a Lead-free Alternative in Electronic Packaging: Materials, Processing, Reliability and Applications, Mater. Sci. Eng. $R$, 2006, 51, p 1-35

5. K.N. Tu and K. Zeng, Tin-Lead (SnPb) Solder Reaction in Flip Chip Technology, Mater. Sci. Eng. R, 2001, 34, p 1-58

6. G. Ghosh, Dissolution and Interfacial Reactions of Thin-film $\mathrm{Ti} / \mathrm{Ni} / \mathrm{Ag}$ Metallizations in Solder Joints, Acta Mater, 2001, 49, p 2609-2624

7. C.Y. Liu, C. Chen, A.K. Mal, and K.N. Tu, Direct Correlation Between Mechanical Failure and Metallurgical Reaction in Flip Chip Solder Joints, J. Appl. Phys., 1999, 85, p 3882-3886

8. E.C.C. Yeh, W.J. Choi, K.N. Tu, P. Elenius, and H. Balkan, Current-Crowding-Induced Electromigration Failure in Flip Chip Solder Joints, Appl. Phys. Lett., 2002, 80, p 580-582

9. C.-M. Chen and S.-W. Chen, Electromigration Effect Upon the $\mathrm{Sn} / \mathrm{Ag}$ and $\mathrm{Sn} / \mathrm{Ni}$ Interfacial Reactions at Various Temperatures, Acta Mater., 2002, 50, p 2461-2469

10. M. Mita, M. Kajihara, N. Kurokawa, and K. Sakamoto, Growth Behavior of $\mathrm{Ni}_{3} \mathrm{Sn}_{4}$ Layer During Reactive Diffusion Between Ni and $\mathrm{Sn}$ at Solid-State Temperatures, Mater. Sci. Eng. A, 2005, 403, p 269-275

11. J. Wang, H.S. Liu, L.B. Liu, and Z.P. Jin, Interfacial Reaction Between Sn-Bi Alloy and Ni Substrate, J. Electron. Mater. 2006, 35, p 1842-1847

12. S.-W. Chen, C.-C. Chen, and C.-H, Chang, Microstructural Evolution of Sn-rich Au-Sn/Ni Flip-Chip Solder Joints Under High Temperature Storage Testing Conditions, Scripta Mater., 2007, 56, p 661-664

13. J. Wang, H.S. Liu, L.B. Liu, and Z.P. Jin, Interfacial Reaction Between Sn-Ag Alloys and Ni Substrate, J. Alloys Compd., 2008, 455, p 159-163

14. T. Laurila, V. Vuorinen, and J.K. Kivilahti, Interfacial Reactions Between Lead-Free Solders and Common Base Materials, Mater. Sci. Eng. R, 2005, 49, p 1-60

15. K. Zeng, R. Stierman, T.C. Chiu, D. Edwards, K. Ano, and K.N. Tu, Kirkendall Void Formation in Eutectic $\mathrm{SnPb}$ Solder Joints on Bare $\mathrm{Cu}$ and its Effect on Joint Reliability, J. Appl. Phys., 2005, 97, p 024508

16. A.B. Vladimirov, V.N. Kaygorodov, S.M. Klotsman, and I.S. Trakhtenberg, Volume Diffusion of 'Silver' Impurities in Nickel, Phys. Met. Metall., 1979, 48, p 107-113

17. D. Marchive, D. Duc, D. Treheux, and P. Guiraldenq, Bulk and Grain-Boundaries Diffusion of Sn in 18-10 Austenitic Stainless-Steel: Study of Ferritization Process at High Temperature, C. R. Acad. Sci., Paris, 1975, 280, p 25-28
18. Y. Iijima, K. Hoshino, M. Kikuchi, and K. Hirano, Interdiffusion and Self-diffusion in Nickel-rich Nickel-Tin Alloys, Trans. Jpn. Inst. Met., 1984, 25, p 234-243

19. L. Kaufman and H. Bernstein, Computer Calculation of Phase Diagrams, Academic Press, New York, 1970

20. B. Sundman, B. Jansson, and J.-O. Andersson, The Program for Optimization, CALPHAD, 1985, 9, p 153-190

21. J.-O. Andersson, L. Höglund, B. Jönsson, and J. Ågren, Computer Simulation of Multicomponent Diffusional Transformations in Steel, Fundamentals and Applications of Ternary Diffusion, G.R. Prudy, Ed., Pergamon Press, New York, 1990, p 153-163

22. J.-O. Andersson and J. Ågren, Models for Numerical Treatment of Multicomponent Diffusion in Simple Phases, J. Appl. Phys., 1992, 72, p 1350-1355

23. A. Borgenstam, A. Engström, L. Höglund, and J. Ågren, DICTRA, A Tool for Simulation of Diffusional Transformations in Alloys, J. Phase Equil., 2000, 21, p 269-280

24. J.E. Morral, B.M. Dupen, and C.C. Law, Application of Commercial Computer Codes to Modeling the Carburizing Kinetics of Alloy Steels, Metall. Mater. Trans. A, 1992, 23A, p 2069-2073

25. A. Engström, L. Höglund, and J. Ågren, Computer Simulation of Diffusion in Multiphase System, Metall. Mater. Trans. A, 1994, 25A, p 1127-1134

26. U.R. Kattner, W.J. Boettinger, and S.R. Coriell, Application of Lukas' Phase Diagram Programs to Solidification Calculations of Multicomponent Alloys, Z. Metallkd., 1996, 87, p 522-528

27. B.-J. Lee, Numerical Simulation of Diffusional Reactions Between Multiphase Alloys with Different Matrix Phases, Scripta Mater., 1999, 40, p 573-579

28. Y. Du and J.C. Schuster, An Effective Approach to Describe Growth of Binary Intermediate Phases with Narrow Ranges of Homogeneity, Metall. Mater. Trans. A, 2001, 32A, p 2396-2400

29. L. Zhang, Y. Du, Y. Ouyang, H. Xu, X.-G. Lu, Y. Liu, Y. Kong, and J. Wang, Atomic Mobilities, Diffusivities and Simulation of Diffusion Growth in the Co-Si System, Acta Mater., 2008, 56, p 3940-3950

30. B. Jönsson, Ferromagnetic Ordering and Diffusion of Carbon and Nitrogen in bcc Cr-Fe-Ni Alloys, Z. Metallkd., 1994, 85, p 498-501

31. B. Jönsson, Assessment of the Mobility of Carbon in fcc C-CrFe-Ni Alloys, Z. Metallkd., 1994, 85, p 502-509

32. B. Jönsson, On Ferrromagnetic Ordering and Lattice Diffusion-A simple model, Z. Metallkd., 1992, 83, p 349-355

33. O. Redlich and A. Kister, Algebraic Representation of Thermodynamic Properties and the Classification of Solutions, Ind. Eng. Chem., 1948, 40, p 345-348

34. H.S. Liu, J. Wang, and Z.P. Jin, Thermodynamic Optimization of the Ni-Sn Binary System, CALPHAD, 2005, 28, p 363-370

35. B. Jönsson, Assessment of the Mobilities of $\mathrm{Cr}, \mathrm{Fe}$ and $\mathrm{Ni}$ in Binary fcc Cr-Fe and Cr-Ni Alloys, Scand. J. Metall., 1995, 24, p 21-27

36. J. Wang, C. Leinenbach, H.S. Liu, L.B. Liu, M. Roth, and Z.P. Jin, Re-assessment of Diffusion Mobilities in the Face-Centered Cubic Cu-Sn Alloys, CALPHAD, 2009, 33, p 704-710 